\title{
A RESOLUÇÃO 135/CNJ E O DESAFIO DA REGULAMENTAÇÃO DA MAGISTRATURA $^{1}$ // Ivan Candido da Silva de Franco ${ }^{2}$
}

\section{Palavras-chave}

regulamentação / controle disciplinar / magistratura / Conselho Nacional de Justiça (CNJ) / Resolução $135 / 2011$

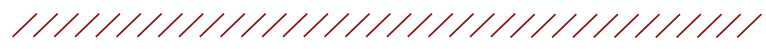

\section{Sumário:}

1 Introdução

2 Dos primeiros passos à Resolução 30/2007 do CNJ.

3 Uniformização definitiva: a Resolução 135/2011 do CNJ

3.1 A elaboração normativa participativa

3.2 Modificações e inovações relevantes

4 Filtro do STF: a ADI 4.638/2012

5 Considerações finais

6 Referências

\section{Resumo}

O Conselho Nacional de Justiça (CNJ), criado em 2004, é o órgão administrativo de cúpula do Poder Judiciário (artigo 103-B da Constituição Federal). Essa instituição conta com competência para editar normas que vinculam os Tribunais brasileiros, com exceção do Supremo Tribunal Federal (STF) e para exercer o controle funcional da magistratura nacional. O presente artigo é um estudo de caso que explora um aspecto específico dessas funções do CNJ em sua atuação: o poder regulamentar em matéria de controle disciplinar da magistratura. Nosso objetivo central é entender a dinâmica institucional existente e como esse tema foi trabalhado ao longo da história do Conselho: que tipos de resistências foram encontrados neste processo e quais atores se envolveram nas discussões existentes. Será descrito e analisado um percurso que se inicia com uma regulação frágil por meio de normas do Regimento Interno, dá lugar a uma primeira resolução unificadora da matéria disciplinar e, finalmente, à norma definitiva, a Resolução $135 / 2011$, a qual promove significativas mudanças no regramento disciplinar - e que, muito por isso, é objeto de uma Ação Direta de Inconstitucionalidade.

\footnotetext{
1 Esse artigo é resultado de reflexões surgidas das discussões no ambiente do XXII Encontro do CONPEDI, bem como de outros espaços acadêmicos. $\mathrm{O}$ artigo original, bastante modificado, tem o título: "Poder Normativo e Controle Disciplinar no Conselho Nacional de Justiça: como ficou a regulamentação dos deveres funcionais dos juízes no Brasil? Um estudo de caso da Resolução 135/2011 do CNJ". Agradeço, em especial, a Luciana Gross Cunha pelo incentivo de publicar este trabalho, a Andréa Gozetto e seu grupo de alunos de Iniciação Científica da UNINOVE pelos comentários críticos, a Natalia Langenegger pela revisão do Abstract e a Gabriella Guimarães pela grande ajuda na revisão do texto.

2 Graduado pela Faculdade de Direito da Universidade de São Paulo (FDUSP) e mestrando em Direito e Desenvolvimento pela Escola de Direito da Fundação Getúlio Vargas (FGV DIREITO SP). E-mail: ivan.csfranco@gmail.com.
} 


\section{CNJ'S RESOLUTION 135 AND THE CHALLENGE OF REGULATING THE JUDICIARY // Ivan Candido da Silva de Franco}

\section{Keywords}

regulation / disciplinary control / judiciary / National Council of Justice (CNJ) / Resolution 135/2011

\section{Abstract}

The National Council of Justice (Conselho Nacional de Justiça - CNJ), created in 2004, is the administrative governing body of the Brazilian Judicial Branch (Article 103-B of the Constitution). It has the responsibility of editing rules that all the Brazilian courts must follow, except the Supreme Court (STF), and of exercising disciplinary control of judges. This article is a case study that explores a specific aspect of the CNJ's mandate: the regulation of the disciplinary control of the judiciary. Our main goal is to understand the existing institutional dynamics and to understand how this issue was undertaken throughout the Council's history: what kind of resistance was encountered in this process and which actors were involved in the ongoing debates. The institutional path, which begins with a fragile regulation from the CNJ's Internal Regiment, and then gives rise to the first resolution of disciplinary matters, is described and analyzed. Ultimately, this path results in the current regulation, the Resolution 135/2011, which promotes significant changes in the disciplinary rules and, because of that a Direct Action of Unconstitutionality (Ação Direta de Inconstitucionalidade -ADI) challenged it before the Brazilian Supreme Court. 


\section{Introdução}

O Conselho Nacional de Justiça (CNJ) é um órgão novo do Poder Judiciário de nosso país. Sua criação ocorreu no bojo da chamada Reforma do Judiciário, feita por meio da Emenda Constitucional 45/2004. O CNJ, então conhecido como o órgão de controle externo da magistratura nacional, representou um dos temas mais controversos do texto que tramitou durante mais de dez anos no Congresso, dividindo opiniões quanto à sua existência e, posteriormente, quanto à sua composição e às suas competências (Sadek, 2001a, pp. 91-92).

A caracterização do Conselho como um órgão de controle externo pode ser entendida como uma forma de dificultar sua criação. Valores como a independência da magistratura foram invocados para justificar a impossibilidade do controle do Poder Judiciário por um órgão externo. Essa argumentação foi utilizada tanto durante a tramitação do Projeto de Emenda à Constituição quanto após sua aprovação. É correto dizer que o CNJ alterou o equilíbrio entre independência judicial e accountability ao ficar encarregado de função fiscalizadora. Porém, o resultado a que se chegou caracteriza um órgão de controle interno, do próprio Poder Judiciário, e não externo (Tomio \& Robl Filho, 2013, p. 36).

Os principais resultados da Reforma, vindos após os debates descritos, foram a aprovação congressual de um Conselho Nacional de Justiça com $60 \%$ de seus membros oriundos da magistratura e a posterior chancela do Supremo Tribunal Federal (STF), que não acolheu os argumentos de inconstitucionalidade do Conselho levantados por associações da magistratura na Ação Direta de Inconstitucionalidade (ADI) 3.367/2005.

As competências do CNJ foram, também, alvo de controvérsias nas discussões da Reforma do Judiciário. 0 surgimento do cargo de Corregedor Nacional de Justiça e as disposições expressas sobre ele, modificadas ao longo das diferentes propostas de redação, indicam a sua importância. A delimitação, maior ou menor, das funções do Conselho no texto constitucional também oscilou. Apesar de haver divergências, elas foram menores do que as existentes em outros temas (Sadek, 2001a, pp. 101-102). Ao final, a competência disciplinar do CNJ ficou rigidamente delimitada no texto constitucional (art. 103-B, § 40), O que fortalece a atuação do órgão.

O presente artigo não pretende abordar o processo da Reforma do Judiciário, tema bastante trabalhado na literatura. ${ }^{3}$ Nosso objetivo é analisar um aspecto específico do Conselho Nacional de Justiça em sua atuação: o poder regulamentar em matéria de controle disciplinar da magistratura. 0 foco está em entender as regulações existentes desde o início do funcionamento do CNJ até o advento da Resolução 135/2011 do CNJ, norma relevante porque uniformiza o procedimento disciplinar aplicável à magistratura nacional. Esse tema nos intriga porque envolve a questão da competência disciplinar do Conselho, algo já descrito como polêmico, e a sua função regulamentadora, outro peculiar aspecto alvo de discussões. 0 desafio da regulamentação da magistratura nacional por apenas um órgão central, recém-criado, será estudado neste artigo em um tema sensível, que é o controle dos deveres funcionais dos juízes.

Interessa-nos entender como esse tema foi trabalhado ao longo da história do Conselho: que resistências foram encontradas neste processo e quais atores se envolveram nas discussões existentes. As diferentes fases regulatórias do Conselho Nacional de Justiça até chegar à Resolução 135/2011 demonstram a dinâmica institucional do CNJ em uma matéria relevante para o cenário jurídico-político nacional.

O processo que envolveu a criação da referida resolução é interessante: a iniciativa isolada de um Corregedor-Geral de Justiça do Estado do Ceará levou a um processo participativo de elaboração normativa que resultou numa resolução que trouxe inovações significativas e foi finalizado numa discussão que ocupou três sessões Plenárias do STF.

A investigação sobre como o CNJ regulamentou o controle disciplinar dos magistrados foi feita por meio de uma pesquisa baseada na amostragem por caso único (Pires, 2008, p. 158), na qual foram desven-

3 Maria Tereza Sadek (2001a, 2001b) descreve as discussões ocorridas durante a tramitação da Emenda Constitucional. Para uma avaliação dos resultados da Reforma do Judiciário à luz dos macroprojetos envolvidos (acesso à justiça ou lógica centralizadora e racionalizadora), ver Luciana Cunha e Frederico de Almeida (2012). 
dados a dinâmica institucional envolvendo um órgão específico e os resultados produzidos na regulamentação de um aspecto de sua atividade. Apesar de articularmos fontes diversas, entendemos que esse é um estudo de caso (único) por conta da amostra ser uma só: regulamentação do controle disciplinar da magistratura pelo CNJ. Pela profundidade com que o tema é estudado, é esperado que, em determinados momentos, utilizemo-nos de fontes até de outras instituições, como o STF, com o fim de melhor compreender nosso objeto.

Nosso trabalho contém as características associadas ao estudo de caso, isto é, trata-se de uma investigação empírica profunda de um fenômeno contemporâneo, na qual os limites entre este e seu contexto não são claros. Ainda, conta com diversas variáveis de interesse, as quais geram plurais fontes de evidência, e conta com algumas proposições teóricas para auxiliar na análise (Yin, 2001, pp. 39-40). O objetivo da escolha deste método pode ser sintetizado da seguinte forma: “(...) não nos interessamos unicamente pelas especificidades do caso em questão (ainda que elas possam ser valorizadas e importantes), mas também por sua capacidade de servir de via de acesso a outros fenômenos ou a outros aspectos da realidade" (Pires, 2008, p. 180). A escolha por apenas um caso do Conselho Nacional de Justiça ocorre pela sua potencial importância para nos fazer entender dinâmicas institucionais do órgão.

Não existiram quaisquer processos administrativos publicados que tenham dado origem ao Regimento Interno do Conselho Nacional de Justiça ou à primeira resolução de procedimentos disciplinares, a Resolução 30/2007. O Regimento Interno foi discutido desde a instalação do Conselho e foi aprovado logo em sua 3 a Sessão Ordinária. Por isso, a fonte utilizada foi a ata da sessão. Segundo informou a Ouvidoria do CNJ a um pedido de acesso à informação (Registro Ouvidoria/CNJ: 78402), a proposta de resolução foi trazida pelo Corregedor Nacional de Justiça, Antônio de Pádua Ribeiro, e aprovada unanimemente pelos demais conselheiros na 6 a Sessão Extraordinária, realizada em 6 de março de 2007. As informações colhidas sobre essa resolução, portanto, são oriundas da ata da sessão e do processo administrativo que resultou na Resolução 135/2011.
A fonte central é o Pedido de Providências 265523.2010 do CNJ, o qual originou a Resolução $135 / 2011$, e que foi selecionado por nos permitir entender a dinâmica do poder regulamentar exercido pelo Conselho Nacional de Justiça. Por meio do estudo da tramitação deste processo administrativo, pudemos entender como ocorreu a elaboração normativa, que decidiu sobre um aspecto ao mesmo tempo relevante e controverso da atuação do CNJ, além de nos dar informações sobre o contexto institucional.

A Ação Direta de Inconstitucionalidade 4.638/2012 também compôs esse estudo por conta de ter como norma questionada, justamente, a Resolução $135 / 2011$. Sua análise é mais panorâmica, com foco nos argumentos levantados na petição inicial e nos dispositivos decisórios utilizados pelo Tribunal no julgamento da Ratificação de Liminar desta ADI. Essa escolha se deve ao foco do estudo, que é o Conselho Nacional de Justiça, sendo o STF mais relevante no que toca à dinâmica entre instituições, e menos na análise argumentativa dos votos dos ministros.

O presente artigo irá descrever todo o percurso referido acima: das regulações iniciais ao questionamento no STF. O caminho realizado tem como objetivo entender o desafio da regulamentação da magistratura nacional, especialmente num caso que lida diretamente com interesses corporativos, como a matéria disciplinar. Dentro desse contexto, irá explorar duas grandes questões de pesquisa. Em primeiro lugar, identificar quais foram os atores envolvidos no processo, tanto internamente ao Conselho Nacional de Justiça quanto em seu questionamento no Supremo. Por último, apontar quais foram as principais inovações trazidas pela Resolução, em seu texto original e após a análise do STF.

Isso será feito tomando como base, preferencialmente, o material disponível eletronicamente no site institucional do Conselho Nacional de Justiça. ${ }^{4}$ Vale a ressalva de que não são todos os atos processuais que se encontram disponíveis para a consulta. Os materiais disponíveis se mostraram uma fonte importante de informação sobre a elaboração norma-

40 endereço do site é: www.cnj.jus.br. É possível acessar processos no link de "Consulta de processos eletrônicos". 
tiva no CNJ. Quando pertinentes, os achados empíricos serão articulados com fontes bibliográficas, de forma a embasar nossas análises.

O texto será dividido em outras quatro seções. Na Seção 2 serão descritos os primeiros passos regulatórios do Conselho em matéria disciplinar, até chegar à elaboração de sua primeira resolução unificadora, a Resolução 30/2007. Na Seção 3, serão analisados aspectos específicos da norma definitiva nesta matéria, a Resolução 135/2011, com foco em seu processo participativo de elaboração normativa e nas principais modificações trazidas pelo texto. Na Seção 4, será descrito o processo de filtro realizado pelo STF, em controle concentrado de constitucionalidade de alguns artigos da referida Resolução 135/2011 do CNJ. Na Seção 5, de considerações finais, serão resumidas as conclusões construídas ao longo do texto.

\section{Dos primeiros passos à Resolução 30/2007 do CNJ}

Para exercer suas competências constitucionais, o CNJ, logo após sua criação, aprovou seu Regimento Interno. Desde sua primeira Sessão Plenária (de 14/06/2005), a redação do Regimento foi discutida, até sua aprovação na $3^{\text {a }}$ Sessão Ordinária, em 16 de agosto de 2005, e publicação, por meio da Resolução 02/2005. Essa norma, como usual em regimentos de órgãos do Poder Público, tinha um escopo bastante amplo e, por isso, não tratou de forma detalhada dos procedimentos disciplinares existentes.

A regulação, ainda que não específica, foi importante por facilitar a atuação do Conselho. Baseou-se, para tanto, na legislação federal aplicável, notadamente na Lei Orgânica da Magistratura Nacional (LOMAN), diploma legal dos anos 1970 que regula os assuntos pertinentes à magistratura. Havia, ainda, referência expressa a outras leis federais que deveriam ser aplicadas, quando pertinentes, aos processos disciplinares.

Após mais de um ano de atuação de controle disciplinar com base nas descritas normas esparsas - Regimento Interno e legislação federal - e pouco específicas quanto aos procedimentos, o CNJ entendeu necessário regulamentar mais detalhadamente a matéria. Neste contexto, na 6a Sessão Extraordiná- ria, de 6 de março de 2007, foi aprovada a Resolução 30/2007 do CNJ. As consideranda que precedem o texto indicam qual foi o diagnóstico que motivou a sua redação (com grifos nossos):

CONSIDERANDO que as normas relativas ao procedimento administrativo disciplinar dos magistrados são muito diversificadas, não obstante tenham de observar as disposições constitucionais e da Lei Orgânica da Magistratura em vigor;

CONSIDERANDO a promulgação da Constituição vigente e das emendas que a alteraram;

CONSIDERANDO que a Lei Complementar no 35, de 1977, é anterior à vigente Constituição Federal;

CONSIDERANDO que as leis de organização judiciária dos Estados, os regimentos dos tribunais e resoluções em vigor sobre a matéria são discrepantes, achando-se muitas normas antes referidas superadas por outras de superior hierarquia;

CONSIDERANDO a necessidade de sistematizar as regras em vigor sobre a matéria, com observância das normas constitucionais e legais em vigor;

Identificamos duas grandes linhas argumentativas que justificaram a elaboração desta resolução. Em primeiro lugar, há o elemento que aparece de forma mais evidente nas consideranda, que é a discrepância entre as normas existentes ou, em outras palavras, a necessidade de uma uniformização a ser realizada pelo órgão central. Além disso, fica clara a intenção de demonstrar que a Lei Orgânica da Magistratura (Lei Complementar 35/1977) não somente é anterior à Constituição como, evidentemente, de hierarquia inferior. Isso nos leva a interpretar que o Conselho passa a mensagem de que seria possível arguir a não recepção desta norma pela Carta Maior ou, mesmo sem isso, que a Constituição seria uma norma posterior e superior à LOMAN.

Ambos os elementos argumentativos são destacáveis porque, por motivos distintos, geraram resistências notadamente em movimentos associativos da magistratura, que apareceram com mais força posteriormente, de forma destacável no questionamento 
judicial no STF, o qual será analisado em detalhe na Seção 4. De forma esquemática, podemos dizer que a regulamentação central realizada pelo CNJ gera resistência daqueles que defendem uma maior autonomia regulatória local, ou seja, que os Tribunais locais definam as próprias normas a serem aplicadas e não se submetam a uma resolução do Conselho. Ainda, há a crítica ao fato de o CNJ regular matérias de sua competência por resolução em contraposição a leis federais. No caso, haveria uma oposição à LOMAN, que seria justificada por estar o Conselho cumprindo uma competência constitucional.

A Resolução 30/2007 foi importante porque foi uniformizou os procedimentos disciplinares aplicáveis à magistratura nacional. Gerou maior segurança aos próprios magistrados ao prever procedimentos mais detalhados e precisos. Houve a explicitação de todas as penas que poderiam ser aplicadas pelo Conselho, as consequências geradas por elas e, mais importante, foram descritos os procedimentos a serem aplicados. Ou seja, houve uma efetiva uniformização, articulando as normas existentes dentro de um todo mais coerente.

Porém, com o tempo, a norma se mostrou defasada, insuficiente para as demandas do Conselho. Essa constatação, da experiência prática dos envolvidos, motivou a mudança normativa objeto do presente estudo. Nascia deste processo a Resolução 135/2011 do CNJ.

\section{Uniformização definitiva: a Resolução 135/2011 do CNJ}

O diagnóstico de que a Resolução 30/2007 não mais correspondia a seus necessários propósitos se mostrou, ao longo do processo de elaboração normativa, ser coletivo. A iniciativa de mudança normativa, todavia, foi individual, tendo partido de um Corregedor-Geral de Justiça do Ceará. Essas questões são expostas pelo Relator do Pedido de Providências estudado, Conselheiro Walter Nunes da Silva Junior, em despacho de janeiro de 2010:

As considerações feitas pelo Corregedor-Geral de Justiça do Estado do Ceará refletem um sentimento geral de que, após quase três anos de efetiva vigência e aplicação prática, faz-se necessário um amplo trabalho de revisão do ato normativo em destaque, matéria que já foi, inclusive, objeto de deliberação em Sessão Administrativa deste Conselho Nacional de Justiça. ${ }^{5}$

Após os quase três anos de vigência, a experiência prática ditava a necessidade de ocorrerem alterações na norma descrita. 0 arcabouço normativo criado não era mais suficiente para lidar com a demanda disciplinar do Conselho. O processo administrativo iniciado desencadeou o processo de modificação normativa, o qual, segundo narra o Relator, foi discutido em Sessão Administrativa do Conselho (de presença reservada aos conselheiros, diferente da Sessão Plenária) e, neste espaço, foi também externada a necessidade de aperfeiçoar a resolução.

\subsection{A elaboração normativa participativa}

Diante dessa situação de adesão à ideia de alterar a uniformização das normas disciplinares do CNJ, e tendo em vista a ampliação do debate, o Relator optou por uma solução interessante de elaboração normativa, decidindo oficiar setores interessados para que se manifestassem sobre propostas de mudança da Resolução 30/2007. Foram intimados todos os Tribunais e Corregedorias do país, bem como as associações de classe da magistratura de âmbito nacional.

Vale destacar que a elaboração normativa do CNJ nem sempre foi porosa à participação de setores que não são parte do próprio órgão. Esse processo de abertura ocorreu por meio de uma alteração normativa discutida e aprovada em Sessão Plenária (RosiIho, 2011, p. 153). ${ }^{6}$ A Resolução 67/2009, que aprovou o novo Regimento Interno, passou a prever a possibilidade de participação em processos do CNJ por

5 Trata-se de trecho de Despacho de 27/01/2010 do Pedido de Providências (PP) 7816-48/2009. Após análise da Corregedoria Nacional de Justiça, os autos foram devolvidos ao relator, só que com numeração distinta: PP 2655-23/2010. Esse processo resultou na aprovação da Resolução 135/2011 pelo Plenário do Conselho Nacional de Justiça.

60 autor afirma que o CNJ tem adotado posturas de experimentalismo institucional no exercício de seu poder normativo (ROSILHO, 2011, pp. 151-154). No caso analisado, duas características centrais mencionadas pelo autor, e que demonstram abertura ao diálogo com a sociedade, estão presentes: a normatização de matéria oriunda de provocação ao Conselho e a revisão de ato normativo anterior. 
meio de audiência pública ou consulta pública (artigo 102 , parágrafos $1^{\circ}$ e $3^{\circ}$, do Regimento Interno do CNJ). Embora o caso estudado não tenha se utilizado de nenhum dos dois expedientes, podemos destacar que a tendência à abertura pode ter influenciado neste processo participativo.

A intenção do relator, como dito, foi a de promover um diálogo amplo com setores possivelmente interessados nas normas disciplinares da magistratura, para que os debates relativos a essas mudanças não ficassem restritos ao âmbito interno do Conselho. Cabe destacar a importância da iniciativa por promover mecanismos de participação na elaboração normativa, o que é bastante relevante em um tema que afetaria a magistratura nacional como um todo, regulada pelo CNJ, que exerce a função constitucional de órgão administrativo de cúpula do Poder Judiciário.

Podemos interpretar essa iniciativa como uma forma de construção de legitimidade do CNJ com os Tribunais. Ao chamá-los para opinar sobre questões que afetam seu cotidiano, o Conselho demonstra uma abertura em dialogar com os envolvidos e uma postura de construção mais coletiva. Oficiar as associações de magistratura, em nossa opinião, faz parte da mesma lógica. Esse mecanismo de elaboração normativa, sem dúvida, representa um avanço em termos de participação. Porém, valeria pensar sobre a possibilidade de participação da sociedade civil em processos como esse. Se considerarmos que os órgãos nacionais da advocacia e do Ministério Público (o Conselho Federal da OAB e a Procuradoria-Geral da República) já oficiam no CNJ por disposição constitucional (art. 103-B, §6º) e, por isso, tiveram a possibilidade de interferir no processo, fica defasada a participação da sociedade civil - organizada e até mesmo de cidadãos. ${ }^{7}$

Pode-se dizer que houve a participação dos setores

7 Uma resposta a essa situação pode ser vista na realização da primeira Audiência Pública pelo CNJ, a qual ocorreu nos dias 17 e 18 de fevereiro de 2014 sobre os temas da eficiência da primeira instância e aperfeiçoamento legislativo voltado ao Poder Judiciário. A iniciativa é destacável justamente por contemplar a possibilidade de participação da sociedade civil organizada, bem como de especialistas nos temas debatidos. Consultas públicas, outra forma relevante de participação, já foram realizadas. convocados. Mais de 40 atores se manifestaram após os ofícios do Conselho e trouxeram seus pontos de vista sobre as principais mudanças que deveriam ser realizadas para uma nova resolução que uniformizasse as normas aplicáveis à magistratura nacional. Seguem, abaixo, os dados coletados que dão conta da participação dos setores interessados:

Quadro 1. Participação dos interessados no processo de elaboração da Resolução 135/2011 do CNJ

\begin{tabular}{|l|c|}
\hline Classe de órgão & $\begin{array}{l}\text { Número de respostas } \\
\text { aos ofícios }\end{array}$ \\
\hline Tribunais Superiores & 01 \\
\hline $\begin{array}{l}\text { Tribunais da Justiça } \\
\text { Estadual }\end{array}$ & 12 \\
\hline $\begin{array}{l}\text { Tribunais da Justiça } \\
\text { Federal (Comum e Espe- } \\
\text { cializada) }\end{array}$ & 22 \\
\hline $\begin{array}{l}\text { Corregedorias da Justi- } \\
\text { ça Estadual }\end{array}$ & 05 \\
\hline $\begin{array}{l}\text { Corregedorias da Jus- } \\
\text { tiça Federal (Comum e } \\
\text { Especializada) }\end{array}$ & 02 \\
\hline Associações de classe & 01 \\
\hline
\end{tabular}

Fonte: voto do Relator no PP 2655. Elaboração própria.

Com relação aos atores envolvidos no processo, os números demonstram a alta adesão de Tribunais de Justiça Estadual e Federal (Comum e Especializada) pelo país. No Quadro 1, discriminamos a participação dos Tribunais e das Corregedorias, mas, como não houve coincidência entre participação dos dois órgãos de um mesmo Tribunal de origem, podemos supor que a contribuição de cada Tribunal foi vocalizada ora pela Presidência e ora pela Corregedoria de Justiça. Dessa forma, tivemos o envolvimento de 41 dos 86 Tribunais que potencialmente poderiam participar. ${ }^{8}$ Chama a atenção o número relativo, chegando quase à metade dos Tribunais, bem como a quan-

8 Consideramos como número total: 27 Tribunais de Justiça Estadual Comum, 3 Tribunais de Justiça Estadual Especializada (Tribunais de Justiça Militares Estaduais), 5 Tribunais Regionais Federais, 27 Tribunais Regionais Eleitorais e 24 Tribunais Regionais do Trabalho. 
tidade de sugestões substantivas realizadas. ${ }^{9}$

Podemos hipotetizar o significado dessa constatação como sendo o de um reconhecimento do Conselho Nacional de Justiça como o órgão administrativo central. O CNJ, atraindo a participação dos Tribunais, demonstrou inserção neles. Mais do que uma resposta à influência do órgão central, podemos interpretar que os Tribunais entenderam que suas contribuições poderiam resultar em uma norma nacional mais bem acabada, o que traria consequências positivas para a atuação local - pautada, necessariamente, pela norma elaborada pelo Conselho.

De outro lado, houve baixa adesão de Tribunais Superiores no processo, vez que apenas o Superior Tribunal Militar respondeu ao ofício do $\mathrm{CNJ}$, afirmando que nada tinha a acrescentar. Poderia ser interpretado que isso se deve ao fato de três dos quatro outros Tribunais Superiores (Supremo Tribunal Federal, Superior Tribunal de Justiça, Tribunal Superior do Trabalho) terem representantes como conselheiros. Porém, acreditamos que essa interpretação é pouco convincente, mesmo porque os ofícios sequer foram respondidos, o que demonstra, no mínimo, pouco cuidado com o processo que vinha se desenvolvendo.

Ainda com relação à participação, destacamos a baixa adesão das Associações de Classe da magistratura de âmbito nacional. Todas foram oficiadas a se manifestar, por conta do evidente interesse sobre a matéria do processo disciplinar aplicável a magistrados, mas, apenas uma respondeu ao ofício, a Associação dos Magistrados Brasileiros (AMB), cuja resposta não demonstrou muito envolvimento com a elaboração porque nada foi substancialmente sugerido. Conclusão possível seria a de que a AMB concorda com as disposições que vinham sendo construídas sobre os deveres funcionais dos magistrados. Não foi isso, porém, o que se verificou, vez que poucos meses depois da aprovação unânime da Resolução 135/2011 pelo

9 Vale mencionar que alguns atores se manifestaram duas vezes ao longo do processo, sendo eles: Corregedoria-Geral de Justiça do Estado de Roraima, Tribunal de Justiça do Estado do Mato Grosso, Tribunal de Justiça do Estado do Pernambuco, Tribunal Regional Eleitoral do Estado do Amazonas, Tribunal Regional Eleitoral do Estado do Piauí e Tribunal Regional do Trabalho da $3^{a}$ Região. No Quadro 1 foram contabilizados apenas uma vez.
Plenário do CNJ, a Associação propôs uma Ação Direta de Inconstitucionalidade tendo por objeto a referida norma (ADI 4.638/2012).

Vale destacar que o associativismo da magistratura, historicamente, teve papel importante na disputa sobre os rumos da justiça estatal, podendo ser considerados atores relevantes do processo (Almeida, 2010, p. 195). O expediente de questionar a constitucionalidade de atos normativos do CNJ tem sido prática comum para associações de classe da magistratura, sendo que mais da metade destas Ações Diretas propostas ao STF - 20 das 32 ações - tinham associações de classe como requerentes (Falcão, Arguelhes, \& Cerdeira, 2012). Ou seja, a judicialização de questões decididas pelo Conselho Nacional de Justiça tem sido uma estratégia recorrente - embora de efetividade questionável, do ponto de vista da procedência das ações - destas associações.

Relativamente ao mérito das discussões no processo de elaboração normativa, destacam-se alguns temas, que apareceram com frequência nas manifestações dos interessados:

I. Procedimento disciplinar: as disposições existentes não eram muito detalhadas. Por isso, foram sugeridas alterações no sentido de regulamentar com mais clareza a forma como se dariam os processos disciplinares. Estabelecimento de etapas, divisão em fases (divididas em capítulos apenas na Resolução 135/2011), clareza nos prazos foram temas recorrentes.

II. Garantias dos magistrados: mais do que apenas regulamentar o modo como se processaria o feito, era necessário destacar expressamente as garantias dos magistrados. Nesse sentido, foram sugeridas disposições específicas para consignar o respeito à ampla defesa, ao contraditório e às demais garantias processuais também existentes no processo administrativo.

III. Competências da Corregedoria: as competências não eram dispostas de forma clara. Com a Corregedoria ganhando força em sua atuação, eram necessários dispositivos que disciplinassem sobre suas competências, para que suas ações não fossem questionadas. 
IV. Publicidade do processo: a Resolução 30/2007 não garantia a publicidade dos atos processuais nem a da aplicação das penas. As contribuições à elaboração da Resolução 135/2011 se posicionavam de modo oposto, procurando dispor sobre a necessidade de publicidade de todos os atos processuais.

Após todo o processo, na Sessão Ordinária realizada em 05 de julho de 2011, a Resolução 135/2011 do CNJ foi aprovada unanimemente pelos conselheiros. Veremos, agora, quais foram os principais resultados (regulatórios) desta norma estudada.

\subsection{Modificações e inovações mais relevantes}

Ao longo dos 6 (seis) anos de funcionamento do Conselho Nacional de Justiça, uma das maiores dificuldades enfrentadas pelo órgão para o bom desempenho das competências a ele confiadas pelo legislador constituinte derivado tem sido compatibilizar o regime jurídico disciplinar aplicável à magistratura, concebido sob um regime de exceção que vigorava no país no ano de 1979, com os princípios que norteiam o devido processo legal no contexto da Constituição de 1988 (Trecho do voto do Relator, Walter Nunes Jr., no PP 2655.)

Como se nota da descrição feita pelo Relator do Processo, a principal missão da nova resolução foi a de atualizar o texto de modo a adequá-lo à atuação prática do Conselho Nacional de Justiça, tendo em vista os valores democrático-constitucionais. Interessante observar que os temas suscitados pelos envolvidos no processo de elaboração foram alvos das mais significativas alterações trazidas.

A primeira inovação, do ponto de vista da própria atividade regulamentar do CNJ, foi a introdução de uma alteração normativa que visava a superar deficiências de uma lei (a LOMAN) em face da Constituição Federal. O trecho transcrito acima deixa clara a expressa tentativa de modificar um texto legal por meio de uma resolução, oriunda de um órgão administrativo. Tal expediente, de inovação no plano jurídico, já havia sido realizado anteriormente pelo $\mathrm{CNJ}$, mas ainda gera críticas severas de quem entende que o órgão deve apenas regulamentar matérias para a mais efe- tiva execução da lei. ${ }^{10}$ O STF, como será demonstrado à frente, referendou essa prática do Conselho.

Do ponto de vista da consolidação do CNJ como órgão administrativo central do Poder Judiciário, o mais relevante foi a previsão expressa de que a regulamentação presente na resolução é nacional. Há discussão com relação à autonomia dos Tribunais, na qual se questiona o fato de um órgão central regular não apenas o seu próprio funcionamento como também estender essa normatização ao âmbito local - discussão essa que foi a mais central na ADI 4.638/2012, que será discutida na Seção 4. Sobrepondo-se a essa polêmica, a Resolução 135/2011 evidenciou o caráter nacional da regulamentação ao estabelecê-la de forma expressa.

O artigo $1^{\circ}$ da resolução deixa claro quais são os alvos da regulamentação: a magistratura nacional, à exceção dos Ministros do Supremo Tribunal Federal.

Art. $1^{\circ}$ Para os efeitos desta Resolução, são magistrados os Juízes Substitutos, os Juízes de Direito e os Desembargadores dos Tribunais de Justiça Estaduais, os Juízes Federais e dos Tribunais Regionais Federais, os Juízes do Trabalho e dos Tribunais Regionais do Trabalho, os Juízes Militares e dos Tribunais Militares, os Juízes Eleitorais e dos Tribunais Regionais Eleitorais, os Ministros do Superior Tribunal de Justiça, os Ministros do Tribunal Superior do TrabaIho, os Ministros do Superior Tribunal Militar e os Ministros do Tribunal Superior Eleitoral, exceto aqueles que também integram o Supremo Tribunal Federal.

O princípio da legalidade foi garantido. Tanto o Regimento Interno quanto a Resolução 30/2007 não tiveram a preocupação de descrever detalhadamente as condutas sancionáveis, o que é questionável num

10 André Ramos Tavares (2009, pp. 24-25) é exemplar neste sentido. Sobre a inovação em sede de poder regulamentar, afirma: "Pretender um órgão como o CNJ, desprovido de qualquer competência jurisdicional ou legislativa, possa construir critérios para aplicá-los e resolver determinadas situações que se lhe afigurem inadmissíveis ou imorais, atenta contra a Constituição. Ainda que isso seja feito em tema deveras sensível e agradável ao público em geral, como foi o caso do nepotismo, a prática deve ser rechaçada de imediato e na sua totalidade, sob pena de desvirtuar o Estado Constitucional e Democrático de Direito instaurado em 1988" (p. 25). 
Estado Democrático de Direito, que deve contar com sólidas garantias processuais. A Resolução 135/2011 procura superar esse problema com algumas medidas, como a divisão da norma em capítulos, fixando as diferentes fases de um processo (investigação preliminar, sindicância, processo administrativo disciplinar). As garantias do magistrado foram também previstas.

Além disso, procurou-se desenvolver uma função preventiva. Foram consolidados, com clareza, os deveres da magistratura, antes presentes apenas na Lei Orgânica da Magistratura Nacional. Dessa forma, o próprio CNJ elaborou um Código de Ética da Magistratura para garantir transparência na exigência de deveres, explicitando e detalhando os termos já previstos na LOMAN.

A Corregedoria Nacional de Justiça, cuja atividade já se destacava em todo o território nacional, foi alçada a um papel proeminente. Os Tribunais passaram a ter o dever expresso de comunicar procedimentos relevantes (como o adiamento ou o julgamento de um procedimento administrativo disciplinar) à Corregedoria Nacional de Justiça. Foi garantido direito a voto em processos disciplinares ao Corregedor Nacional de Justiça. ${ }^{11}$ Sua autonomia foi aumentada, por certo. Por todas as normas, destacamos uma que demonstra a amplitude desse novo papel assegurado:

Art. 13. O processo administrativo disciplinar poderá ter início, em qualquer caso, por determinação do Conselho Nacional de Justiça, acolhendo proposta do Corregedor Nacional ou deliberação do seu Plenário, ou por determinação do Pleno ou Órgão Especial, mediante proposta do Corregedor, no caso de magistrado, de primeiro grau, ou ainda por proposta do Presidente do Tribunal respectivo, nas demais ocorrências.

Por último, vale destacar a garantia da publicidade como regra. O contraste com a normatização anterior é notável. Há uma verdadeira inversão nos valores:

11 Um processo apenso ao PP 2655 discutia esse ponto. Trata-se da Consulta 4991-97/2010, que questionava essa função da Corregedoria. A opção normativa do $\mathrm{CNJ}$ foi a de garantir o direito ao voto, de um lado (art. 14, § $3^{\circ}$ ), e limitar a relatoria do Processo Administrativo Disciplinar para conselheiros que não tenham dirigido o procedimento preparatório (art. 14, § $8^{\circ}$ ). na Resolução 30/2007, seguindo o regramento da LOMAN, preservava-se preferencialmente a intimidade; já na Resolução 135/2011, o interesse público de uma sessão aberta é o valor preferencial. Os trechos transcritos abaixo demonstram o descrito:

\section{Resolução 30/2007}

Art. 23. Em razão da natureza das infrações objeto de apuração ou de processo administrativo, nos casos em que a preservação do direito à intimidade do interessado no sigilo não prejudique o interesse público à informação, poderá a autoridade competente limitar a publicidade dos atos ao acusado e a seus advogados.

\section{Resolução 135/2011}

Art. 20. O julgamento do processo administrativo disciplinar será realizado em sessão pública e serão fundamentadas todas as decisões, inclusive as interlocutórias.

$\S 1^{\circ} \mathrm{Em}$ determinados atos processuais e de julgamento, poderá, no entanto, ser limitada a presença às próprias partes e a seus advogados, ou somente a estes, desde que a preservação da intimidade não prejudique o interesse público.

O contraste entre essas normas demonstra um pouco das mudanças trazidas pela Resolução 135/2011. Se a anterior já regulava de forma distinta à Lei Orgânica da Magistratura Nacional, essa nova resolução trouxe mudanças ainda mais significativas, representando, em casos como o exposto acima, verdadeiras inovações ao fechado âmbito da magistratura. Pouco tempo depois de sua aprovação no Plenário do Conselho, foi proposta uma Ação Direta de Inconstitucionalidade no Supremo Tribunal Federal tendo como objeto diversos de seus dispositivos.

\section{Filtro do STF: a ADI 4.638/2012}

Antes de adentrarmos no estudo da ADI propriamente, vale reservar algumas linhas para considerações sobre o contexto político-institucional do momento. Pode-se dizer que havia, na sociedade, uma divisão acerca de qual deveria ser o papel do Conselho Nacional de Justiça e, mais especificamente, da Corregedoria Nacional de Justiça nos processos disciplina- 
res contra magistrados. A questão central era saber qual seria o limite da atuação do CNJ, ou seja, se sua competência disciplinar constitucional seria concorrente à dos Tribunais ou subsidiária. Questionava-se, em outras palavras, se a Corregedoria Nacional de Justiça poderia processar disciplinarmente juízes sem que o órgão local tivesse atuado anteriormente. A Associação dos Magistrados Brasileiros (AMB) vocalizou a insatisfação com a atuação do CNJ e propôs a referida Ação Direta de Inconstitucionalidade.

Essas visões opostas travaram debates públicos relevantes à época. Para explicitar esta conjuntura, é válido recorrermos a duas figuras centrais no Conselho Nacional de Justiça, que eram grandes representantes destas opostas visões. De um lado, o Presidente do STF e do CNJ, Ministro Cezar Peluso, que defendia a maior autonomia dos Tribunais e, portanto, a necessidade de um processamento anterior para que só então atuasse o Conselho. De outro lado, a Corregedora Nacional de Justiça, Ministra Eliana Calmon, que defendia uma postura mais ativa do $\mathrm{CNJ}$, que, na inação da Corregedoria ou Tribunal Local, poderia processar originariamente quaisquer magistrados.

A polarização foi tamanha que o assunto tomou um jornal de grande circulação no país, em 27 de setembro de 2011, contendo declarações da Corregedora com severas críticas à impunidade da magistratura. Nesta reportagem, ela utilizou a depois bastante conhecida expressão dos "bandidos que estão escondidos atrás da toga". ${ }^{12}$ No mesmo dia, na 135 a Sessão Ordinária do Conselho Nacional de Justiça, o Presidente leu uma nota, em nome do CNJ, na qual se fazia uma defesa da magistratura, que estaria sendo ofendida de forma generalizada com as declarações publicadas naquele dia.

A ADI 4.638/2012 é proposta neste contexto. No último dia de expediente forense do ano de 2011, ainda não tendo sido apreciada pelo Plenário do Supremo Tribunal Federal, o Ministro-Relator Marco Aurélio decide apreciar os pedidos em caráter liminar e concede decisões, em regra, favoráveis às pretensões da

12 Reportagem veiculada na Folha de S. Paulo do dia 27 de setembro de 2011. Disponível em: <http://www1.folha.uol.com.br/fsp/ poder/po2709201107.htm>. Acesso em: 1 fev. 2014.
AMB. Na primeira Sessão Plenária do ano seguinte, 2012, o STF se debruçou sobre este processo, em sede de Ratificação de Liminar. o julgamento, que passaremos a descrever, durou três sessões inteiras.

Os questionamentos da AMB à Resolução 135/2011 do CNJ foram de ordem formal e material. Do ponto de vista formal, questionou-se a competência do Conselho Nacional de Justiça em regulamentar uma Resolução aplicável à magistratura nacional. Para a $\mathrm{AMB}$, não só não havia atribuição expressa de competência para a normatização, como também a atuação do CNJ estaria ferindo a separação de Poderes ao atropelar a autonomia dos Tribunais. Do ponto de vista material, podemos dividir os questionamentos de diversos dispositivos em quatro grandes grupos: violação das garantias dos magistrados, sigilo por interesse público, autonomia dos tribunais e competência disciplinar do CNJ.

A grande tese de questionamento formal da Associação de Magistrados Brasileiros, relativa à incompetência normativa do CNJ, foi rejeitada. O STF entendeu que o CNJ tem a possibilidade de editar normas que afetem a magistratura nacional. Esse entendimento reforçou o papel do Conselho como órgão administrativo central da magistratura, contrariando os interesses dos que entendiam que a autonomia local deveria ser maior.

Com relação aos questionamentos materiais dos dispositivos da Resolução 135/2011 do CNJ, houve teses vencedoras, mas, de forma geral, pode-se dizer que a decisão como um todo tampouco foi favorável à AMB. Na categoria da violação das garantias dos magistrados, importantes teses foram aceitas, como a fixação de um regime legal único, a LOMAN, rejeitando a possibilidade de aplicação de penas previstas em outros diplomas (art. $3^{\circ}, \S 1^{\circ}$ ), bem como a retirada do afastamento cautelar - que possibilitava, de forma muito ampla, o afastamento do magistrado para apuração da infração disciplinar (art. 15, § $1^{\circ}$ ).

Contrariamente ao entendimento da AMB, porém, decidiu o STF por dar interpretação conforme a Constituição ao dispositivo do parágrafo único do art. 21, o que significou um novo regime de deliberação na aplicação da pena administrativa, que deve se dar 
em votações específicas sobre cada pena até que se atinja a maioria absoluta dos votos. Pelo texto original da Resolução 135/2011, deveria ser aplicada a pena mais leve e, segundo a interpretação da AMB, se nenhuma das penas sugeridas pelos julgadores atingisse a maioria absoluta numa deliberação, nenhuma pena poderia ser aplicada.

$\mathrm{Na}$ categoria do sigilo por interesse público, todas as teses da AMB foram rejeitadas. Penas que antes eram aplicadas "reservadamente, por escrito", na dicção da LOMAN, foram adaptadas a uma aplicação pública (art. $4^{\circ}$ ). Os julgamentos de matéria disciplinar são, em regra, públicos (art. 20, § $2^{\circ}$ ). Apesar do questionamento da Associação, que entendia como compatível com o Estado Democrático de Direito o regime de sigilo no processo administrativo disciplinar por interesse público, o STF fixou a publicidade como regra, mesmo nestes procedimentos mais sensíveis.

O referendo do Supremo Tribunal Federal a um dispositivo de uma Resolução de um órgão administrativo que contraria expressamente uma lei federal é notável. A argumentação do STF vai no sentido de que normas constitucionais imporiam a necessidade desta decisão - segundo a qual a publicidade é a regra, ao contrário do que dispõe a LOMAN. Poderíamos interpretar essa decisão como um sinal de que o Supremo entende que, ao menos em parte, a Lei Orgânica da Magistratura Nacional não deveria ser recebida pelo ordenamento constitucional. Além disso, podemos levantar a hipótese de que o STF, que desde a promulgação da Constituição não exerceu seu dever de iniciativa sobre Lei Complementar a tratar do Estatuto da Magistratura (art. 93, da Constituição Federal), permite alterações nesta legislação, considerada defasada. ${ }^{13}$

$\mathrm{Na}$ categoria da autonomia dos Tribunais, houve conquistas pontuais da AMB e seguidas rejeições de teses. As conquistas, refletidas em alterações de diversos dispositivos da Resolução, referem-se à não imposição do órgão competente de cada Tribunal

13 No ano de 2013, em mais uma tentativa de elaborar um Anteprojeto de Lei Complementar, o Ministro Presidente do STF e do CNJ, Joaquim Barbosa, emitiu Portaria (47, de 18 de fevereiro de 2013) na qual qualifica a LOMAN como defasada e alvo de litígios decorrentes de sua recepção ou não à Constituição. para processar ou julgar administrativamente um magistrado. Todos os dispositivos que fixavam um órgão específico foram substituídos pela locução "órgão competente do Tribunal” (arts. $8^{\circ}, 9^{\circ}, \S 2^{\circ}, \S 3^{\circ}$ ).

Nessa mesma categoria, porém, foram rejeitadas teses que não reconheciam a competência do CNJ para editar normas de caráter nacional. Esse entendimento é muito similar ao apresentado no questionamento formal, o que levou o STF, da mesma forma, a não acoIher as teses da AMB. O Supremo, também, autorizou a ampliação do rol dos legitimados a representar contra magistrados (art. $9^{\circ}$ ) e a regulamentação sobre procedimentos, como o direito a voto do Presidente e do Corregedor, que afetam os Tribunais (art. 14, §§ $3^{\circ}, 7^{\circ}$, $\left.8^{\circ}, 9^{\circ}\right)$. A aplicação preferencial das normas emanadas pelo CNJ fica evidente no parágrafo único do art. 12, referendado pelo STF, que assim determina:

Art. 12. Para os processos administrativos disciplinares e para a aplicação de quaisquer penalidades previstas em lei, é competente o Tribunal a que pertença ou esteja subordinado o Magistrado, sem prejuízo da atuação do Conselho Nacional de Justiça.

Parágrafo único. Os procedimentos e normas previstos nesta Resolução aplicam-se ao processo disciplinar para apuração de infrações administrativas praticadas pelos Magistrados, sem prejuízo das disposições regimentais respectivas que com elas não conflitarem.

Na categoria da competência disciplinar do CNJ, a tese central da AMB foi rejeitada. Desmembramos esse questionamento em uma nova categoria por conta de sua relevância, apesar de a discussão ser de autonomia dos Tribunais ou de limitação da competência da Corregedoria Nacional de Justiça. Esse questionamento é a síntese dos embates descritos anteriormente, que representavam a visão que se tinha do papel do Conselho Nacional de Justiça na sociedade. Estava em pauta o caráter da competência do CNJ: subsidiário ou concorrente (art. 12, caput, transcrito acima). Segue trecho relevante da argumentação da AMB exposta em sua petição inicial:

Enquanto a Constituição atribui uma "competência" "disciplinar" para o CNJ "sem prejuízo" da 
competência "disciplinar" "originária" dos "Tribunais" - o que pressupõe a abertura da competência do CNJ somente se e quando o Tribunal não exercitar a sua competência disciplinar de forma adequada - a Resolução fixou uma competência disciplinar para os Tribunais "sem prejuizo" da competência do CNJ, o que pressupõe a supremacia da competência do CNJ em detrimento da competência dos Tribunais.

Esse foi o tema que mais gerou polêmica no Tribunal. A matéria foi decidida pela maioria mínima: cinco votos favoráveis à tese de que o CNJ tem competência concorrente com os Tribunais, podendo avocar processos que entender relevante, contra quatro votos alinhados à tese da $\mathrm{AMB}$, segundo a qual o CNJ somente poderia atuar de forma subsidiária aos Tribunais.

O julgamento deste dispositivo é, possivelmente, o melhor exemplo do que estava em jogo na Ação Direta como um todo: a contraposição de uma visão mais centralizadora a uma visão mais descentralizadora. Mais do que isso, decidia-se, naquele momento, sobre qual seria o papel das investigações e dos processos conduzidos pela Corregedoria Nacional de Justiça e, portanto, pelo Conselho Nacional de Justiça. É inegável o caráter político e de disputa de poder que ocorreu naquele momento, envolvendo competência, ou, em outras palavras, poder. Um verdadeiro conflito federativo que, em última análise, resultaria na maior ou menor autonomia do órgão administrativo nacional do Poder Judiciário. Saiu vencedor o CNJ, com a possibilidade de processamento originário pelo órgão nacional, vencendo a tese da necessidade de apreciação prévia pelos Tribunais.

Por último, é importante destacar que o julgamento do Supremo Tribunal Federal ainda não foi definitivo. A decisão existente até o momento foi dada em sede de Referendo de Liminar. Isso significa que, com uma nova composição, o STF poderia reverter a decisão, principalmente a referente à competência disciplinar, que, vale lembrar, foi tomada por maioria mínima. A ausência de decisões definitivas em controle concentrado sobre atos do CNJ é uma marca do Supremo Tribunal Federal (Falcão, Arguelhes, \& Cerdeira, 2012). Isso poderia indicar que o STF, em algum grau, legitima o CNJ ao não decidir sobre questiona- mentos judiciais ou decidir em caráter provisório. 0 fato de o próprio STF poder reverter as decisões postergadas ou liminarmente prolatadas indica a manutenção, nas mãos do Supremo, de parcela de controle sobre a atuação do Conselho.

Pode-se dizer que a Resolução 135/2011 foi ligeiramente modificada. Alguns dispositivos foram declarados inconstitucionais, como o que previa o afastamento cautelar sem deliberação plenária, e outros receberam interpretação conforme, como o relativo à deliberação acerca das penas. Mas, de forma geral, a norma manteve sua feição anterior, sendo destacáveis o referendo quanto ao caráter nacional da resolução e a manutenção da competência disciplinar do CNJ. Ou seja, as grandes modificações e inovações trazidas pela resolução permaneceram após o filtro do STF - o qual, como dito, pode ser reformado pela decisão do mérito da Ação em plenário.

\section{Considerações finais}

Este texto teve o objetivo de descrever, a partir de materiais colhidos majoritariamente do Conselho Nacional de Justiça, dinâmicas institucionais importantes em torno de uma questão conturbada - o controle disciplinar dos magistrados. Descrevemos o processo que levou à elaboração de uma Resolução do CNJ sobre a matéria, bem como as inovações trazidas pela norma e a contraposição de interesses envolvida na matéria. Apesar das limitações do estudo do caso, que envolve mais do que um processo administrativo do CNJ, Sessões Plenárias e a decisão do Supremo Tribunal Federal, algumas das conclusões podem contribuir para uma melhor compreensão do papel representado pelo Conselho Nacional de Justiça em nosso país, órgão ainda pouco explorado nas pesquisas em direito.

O artigo descreve brevemente o surgimento do Conselho Nacional de Justiça para chegar à sua atuação prática, com foco na regulamentação do controle disciplinar. Num espaço de aproximadamente seis anos, normas regimentais genéricas deram lugar a uma resolução específica que, por fim, abriu caminho a uma última norma unificadora dos procedimentos disciplinares: a Resolução 135/2011. Seu processo de elaboração partiu de uma iniciativa isolada de 
um Corregedor-Geral de Justiça. Resultou dessa iniciativa um processo participativo, incentivado pelo Relator do Processo, Conselheiro Walter Neves Jr., que oficiou os interessados no processo: Tribunais e Corregedorias de todo o país, além de associações de classe da magistratura de âmbito nacional.

Foi destacável a participação dos Tribunais, que se engajaram no processo, enviando sugestões de alterações à defasada Resolução 30/2007. Os Tribunais Superiores tiveram participação reduzida: dos cinco, apenas o Superior Tribunal Militar se manifestou, nada acrescentando ao texto. As associações de classe, também, tiveram participação discreta. Das cinco associações oficiadas, apenas a AMB se manifestou, tampouco acrescentando algo ao texto. Isso possivelmente se deve à preferência por outros foros de disputa, como o Poder Judiciário - representado pelo STF, competente para analisar matérias relativas ao CNJ (art. 101, I, r, da Constituição Federal).

A Resolução 135/2011, aprovada unanimemente em Sessão Plenária do Conselho Nacional de Justiça, trouxe algumas inovações relevantes ao controle disciplinar. Sintetizando em um grande objetivo essa mudança normativa, ocorrida menos de quatro anos depois da resolução anterior (elaborada pelo mesmo Conselho), pode-se dizer que foi o da atualização do texto, contando com um regramento mais organizado e com disposições baseadas diretamente da Constituição Federal de 1988 - mesmo que em expressa oposição à lei federal que rege a matéria, a LOMAN. Como inovações significativas, podemos destacar a consolidação do CNJ como fonte nacional de normas para a magistratura; a efetivação do princípio da legalidade, com clareza nos procedimentos cabíveis e das garantias dos magistrados; a publicidade como regra, tanto nos julgamentos quanto na aplicação das penas; e, um papel mais proeminente e centralizador da Corregedoria Nacional de Justiça, com expressas previsões normativas que garantem o seu trabalho por todo o território nacional.

Num contexto de forte polarização de visões acerca do papel que deveria ser desempenhado pela Corregedoria Nacional de Justiça, e, portanto, pelo CNJ, nas investigações e processos disciplinares de magistrados, foi proposta a Ação Direta de Inconstitu- cionalidade 4.638/2012. A Associação de Magistrados Brasileiros, requerente, vocalizando setores insatisfeitos com a ativa atuação do Conselho em matéria disciplinar, questionou a resolução 135/2011 no STF.

O julgamento do Plenário, após decisão monocrática do Ministro-Relator Marco Aurélio, foi em sede de Referendo de Liminar. Nele, foram fixadas algumas balizas importantes para a aplicação da Resolução 135/2011. O aspecto mais relevante foi o da manutenção da competência disciplinar do Conselho Nacional de Justiça, decisão contrária aos interesses da AMB e tomada pela maioria mínima dos membros do Supremo. Esse resultado - ainda que provisório, porque tomado em sede de Referendo de Liminar - garantiu uma maior autonomia da Corregedoria Nacional de Justiça e, por consequência, do próprio CNJ.

Sobre a norma que regula os procedimentos disciplinares aplicáveis à magistratura, a Resolução $135 / 2011$, a qual foi pouco alterada pelo STF, pode-se dizer, entre outros aspectos, que: o procedimento disciplinar ficou mais claro, sendo ainda mais evidenciadas as garantias da magistratura; a publicidade foi assegurada como regra, ao contrário do que entendia a AMB; e, garantiu-se o caráter nacional do Conselho, ao entender como constitucionais a regulamentação nacional da magistratura, contrariando interesses de autonomia dos Tribunais.

Esse caminho percorrido pela pesquisa demonstra a gama de interesses existentes na sociedade brasileira. Nesse caso, ficaram claras as divergências que permeiam os processos político-institucionais no país. Ainda mais quando envolvem setores de prestígio, como a magistratura. O presente artigo, como dito, não pretende expandir suas conclusões para muitos outros casos. Mas, isto sim, contribuir para a compreensão de fenômenos como esse que dão conta do que significa consolidar uma instituição nova no país, que muda o status quo ante e que, por isso, pode gerar resistências.

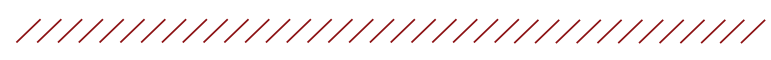




\section{Referências}

Almeida, F. N. R. (2010). A nobreza togada: as elites jurídicas e a política da justiça no Brasil. (Tese de Doutorado). Universidade de São Paulo, São Paulo, SP.

Cunha, L. G., \& Almeida, F. (2012). Justiça e desenvolvimento econômico na reforma do Judiciário brasileiro. In M. Schapiro, D. Trubek (Eds.), Direito e Desenvolvimento: um diálogo entre os Brics. São Paulo: Saraiva.

Falcão, J., Arguelhes, \& D. W, Cerdeira, P. C. (2012). 0 diálogo entre o CNJ e o Supremo. Revista Interesse Nacional, 4(16).

Pires, A. (2008). Amostragem e pesquisa qualitativa: ensaio teórico e metodológico. In J. Poupart, J. P. Deslauriers, L. H. Groulx, A. Laperrière, R. Mayer, A. P. Pires (Eds.), A Pesquisa Qualitativa: enfoques epistemológicos e metodológicos. Petrópolis: Editora Vozes.

Rosilho, A. J. (2011). O poder normativo do CNJ: um caminho para se pensar o experimentalismo institucional. Revista Brasileira de Estudos Constitucionais - RBEC, 5(20), 141-160.

Sadek, M. T. (2001a). Controle Externo do Poder Judiciário. In M. T. Sadek (Ed.). Reforma do Judiciário (pp. 91-180). São Paulo: Fundação Konrad Adenauer.

Sadek, M. T. (2001b). Os juízes e a reforma do judiciário: textos para discussão. São Paulo: IDESP.

Tavares, A. R. (2009). O Conselho Nacional de Justiça e os limites de sua função regulamentadora. Revista Brasileira de Estudos Constitucionais - RBEC, 3(9), 13-26.

Tomio, F. R. L., \& Robl Filho, I. N. (2013). Accountability e independência judiciais: uma análise da competência do Conselho Nacional de Justiça. Revista de Sociologia e Política, 21(45), 29-46.

Yin, R (2001). Estudo de Caso: planejamento e métodos. Porto Alegre: Bookman.

\section{Fontes documentais}

Supremo Tribunal Federal, Pleno, Ratificação de Liminar na Ação Direta de Inconstitucionalidade 4.638, Rel. Min. Marco Aurélio, j. 08/02/2012.

Conselho Nacional de Justiça, Plenário, Consulta 4991-97.2010, Rel. Cons. Walter Nunes da Silva Júnior, j. 19/10/2010.

Conselho Nacional de Justiça, Plenário, Pedido de
Providências 2655-23.2010, Rel. Cons. Walter Nunes da Silva Júnior, j. 05/07/2011.

Conselho Nacional de Justiça, Plenário, Pedido de Providências 7816-48/2009, Rel. Cons. Walter Nunes da Silva Júnior, sem julgamento.

Data de submissão/Submission date: 03.02.2014

Data de aceitação para publicação/Acceptance date: 29.11.2014 